\title{
La Universidad de Chile entrega Medalla Rectoral al Profesor Dr. Myron Levine
}

\author{
El siguiente es el texto del discurso que el Dr. Myron Levine pronunciara al recibir un \\ reconocimiento de la Universidad de Chile, con fecha 10 de enero 2006, por su contribución al país y a \\ la salud pública chilena.
}

"Señor Rector de la Universidad de Chile, Profesor Luis Riveros; Señor Pro-Rector de la Universidad de Chile, Dr. Jorge Litvak; Señor Decano de la Facultad de Medicina, Dr. Jorge Las Heras; Dra. Valeria Prado, Directora del Programa de Microbiología y Micología del Instituto de Ciencias Biomédicas; Dra. María Eugenia Pinto, Directora de la Escuela de Post-Grado de la Facultad de Medicina; distinguidos colegas y colaboradores; queridos amigos:

No encuentro palabras para expresar la alegría, el honor y la gratitud que siento al recibir esta Medalla Rectoral. En preparación para esta ceremonia tuve la oportunidad de hacer un recuento de mis 28 años de relación con Chile; recordar las personas que he conocido y los proyectos que hemos realizado juntos, en varios lugares de este hermoso país. Es imposible trasmitir tantos años y tantas buenas experiencias en pocos minutos. Para hacerlo de una forma más o menos ordenada y breve quisiera dividir estas casi 3 décadas de trabajo en Chile en 4 periodos:

- la época de la fiebre tifoidea (más o menos entre 1978 y 1989);

- el periodo de los estudios epidemiológicos y bacteriológicos de la diarrea infantil, en poblaciones y campamentos de Santiago (1985-1992);

- la época del cólera (1991-1993) y, finalmente,

- el periodo de estudios de las infecciones respiratorias agudas y de infecciones invasoras bacterianas, desde principios de los años 90 hasta ahora, que coincide con la creación de la Fundación Centro para Vacunas en Desarrollo-Chile, CVD-Chile.

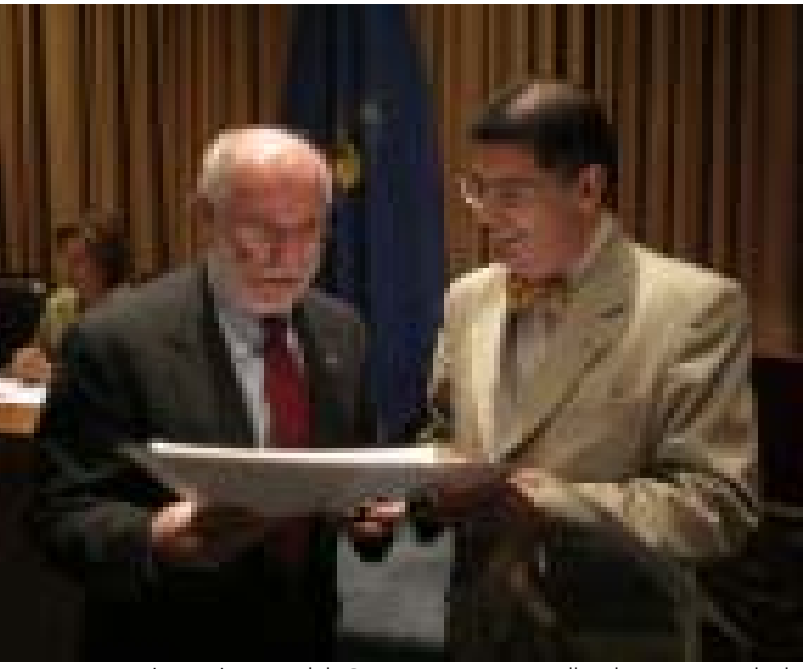

Dr. Myron Levine, Director del Centro para Desarrollo de Vacunas de la Universidad de Maryland y Prof. Luis Riveros C. Rector de la Universidad Chile Fotografía: Pablo Madariaga. Propiedad Universidad de Chile).
Cuando llegué a Chile por primera vez, a fines de octubre de 1978, encontré una ciudad encantadora, rodeada de colinas plagadas con las flores de primavera. Invitado por el Ministerio de Salud, pasé un mes trabajando como asesor de la Organización Panamericana de la Salud, para esclarecer las causas de la altísima endemia de fiebre tifoidea en la Región Metropolitana, donde 96\% de la población tenía acceso a agua potable y $80 \%$ tenía alcantarrillado. No parecía comprensible que la fiebre tifoidea fuera un problema, en una ciudad con esta infraestructura sanitaria!! Durante las semanas que siguieron a mi llegada conocí muchos individuos en numerosas instituciones chilenas, que rápidamente llegaron a ser mis colaboradores y amigos. Con muchos de ellos he mantenido lazos de colaboración y amistad hasta ahora, incluyendo varios colegas en los Departamentos de Pediatría y de Micro- biología de la Universidad de Chile; otros en el Instituto de Salud Pública; otros en los diversos hospitales estatales de la Región Metropolitana; otros en el Ministerio de Salud y los Servicios de Salud.

En noviembre de 1978 fui a la Región de Los Lagos para hacer un estudio sero-epidemiólogico de anticuerpos anti-antígeno $\mathrm{H}$ de Salmonella Typhi, en una población con baja notificación de fiebre tifoidea. Esta población sirvió como control para examinar la alta seropositividad que encontramos en escolares adolescentes de la Región Metropolitana. En esa zona encontré un paisaje tan hermoso y tan cautivador, que quise quedarme allí por mucho más tiempo.

Al comienzo del año 1979 escribí los primeros grants para apoyar estudios epidemiológicos y de microbiología ambiental sobre la fiebre tifodea endémica $y$, en conjunto con el extinto Dr. José Manuel Borgoño Domínguez, establecimos el Programa de Control de la Fiebre Tifoidea en el Ministerio de Salud. En poco tiempo, el programa llegó a tener una reputación internacional. Demostramos que el uso de aguas servidas para cultivar verduras consumidas en ensaladas, era la principal causa de la endemia de fiebre tifoidea en Santiago. En paralelo realizamos cuatro grandes ensayos en el terreno, que abarcaron 465.000 escolares de Santiago, para medir la eficacia de la vacuna oral Ty21a en la prevención de la enfermedad, y evaluarla como herramienta de control.

Entre los primeros colegas y colaboradores que conocí en esos años, debo mencionar a la Dra. Valeria Prado Jiménez, entonces 
Microbióloga del Hospital Calvo Mackenna; a la Dra. María Eugenia Pinto Claude, Microbióloga y docente del Hospital San Juan de Dios; y a Isidoro Horwitz Campos y Alfredo Avendaño Bertoglio, infectólogospediatras en el Hospital Roberto del Río. Todos ellos tenían gran motivación por contribuir a resolver el problema de la fiebre tifoidea en niños chilenos. La Profesora Prado ha sido mi colaboradora en forma ininterrumpida durante estos casi 30 años; Isidoro y Alfredo siguen siendo mis amigos, y continúan siendo un gran apoyo y estímulo para continuar trabajando en Chile.

Durante el tiempo de la fiebre tifoidea viví en Santiago varios meses por cada año. Sin embargo, debido al rápido crecimiento del programa, fue necesario identificar un individuo que pudiera dedicar $100 \%$ de su esfuerzo a asegurar su óptimo funcionamiento. Una joven y entusiasta epidemióloga chilena, recién graduada de su beca en Salud Pública, la Dra. Catterine Ferreccio Readi, asumió esa responsabilidad y permaneció en este cargo durante casi diez años. Junto con Catherine y su equipo estudiamos la epidemiología de la enfermedad e identificamos métodos para controlarla.

En la época en que empezamos los estudios de diarrea infantil, hacia fines de $\operatorname{los} 80$, Valeria Prado migró del Hospital Luis Calvo Mackenna al Departamento de Microbiología del Campus Oriente de la Universidad de Chile. En la unidad de la Dra. Prado introdujimos técnicas de biotecnología de punta para ese tiempo. Antes de la aparición de la RPC como método de diagnóstico, utilizamos sondas genéticas para identificar las categorías de Escherichia coli diarreogénica. Rápidamente, el trabajo de la Dra. Prado, pionera en la aplicación de esta tecnología, adquirió prestigio y reconocimiento en toda América Latina. Microbiólogos de varios países de la Región vinieron a capacitarse en su laboratorio. Es imposible olvidar la generosidad y el entusiasmo con que ella acogió a los profesores y becados que vinieron a aprender de su experiencia. Posteriormente, la Dra. Prado aplicó estas tecnologías para estudiar las cepas de E. coli entero-hemorrágica que causan el síndrome hemolítico urémico en Chile.

En el verano de año 91 el cólera reapareció en Latinoamérica. Una pandemia extensa afectó la región, después de un siglo de ausencia. Tuve la oportunidad de visitar Perú en los primeros días de marzo de ese año, y constatar que en los hospitales de Lima prevalecía una situación muy similar a la que había conocido anteriormente en Bangladesh y países en África, durante brotes de cólera. Poco después de mi visita a Perú escribí una carta al Ministro de Salud de Chile, expresando mi preocupación por la posibilidad de que Vibrio cholerae pudiera llegar a la Región Metropolitana y diseminarse en la población a través del uso de aguas servidas, tal como había ocurrido con el bacilo de la fiebre tifoidea. El Ministro de Salud de ese tiempo, el Dr. Jorge Jiménez de la Jara, me pidió venir a Chile para presentar una charla ante las autoridades del Ministerio. La charla tuvo lugar un día viernes $\mathrm{y}$, para mi sorpresa, no estimuló mucho interés entre los asistentes. La discusión y las preguntas que siguieron a mi exposición denotaron mucho escepticismo de parte de las autoridades, sobre la posibilidad de que en Chile pudiera ocurrir un problema como el que estaba afectando a Perú. El cólera, dijeron, no podrá entrar a un país con las condiciones socioeconómicas y sanitarias existentes en Chile. ¡Pero el Vibrio cholerae O1 El Tor no estuvo de acuerdo! Durante el fin de semana inmediatamente siguiente, el primer caso índice de cólera hizo su aparición en Santiago. El paciente fue un hombre vegetariano, que había consumido ensaladas crudas en los dos días previos al comienzo de su diarrea profusa. El cólera había llegado a Chile; en las tres semanas siguientes ocurrió un brote de 41 casos, que causó gran alarma entre la población y las autoridades de salud.

Demostrando un enorme coraje político y buena práctica de la medicina preventiva, el Dr. Jorge Jiménez convenció al gobierno chileno para que prohibiera el uso de aguas servidas en el cultivo de hortalizas en la Región Metropolitana y en todo el resto del país. La medida no sólo consiguió abortar el brote de cólera sino que, en pocos meses, logró reducir en forma dramática el problema de fiebre tifoidea endémica que había afectado a la región durante muchas décadas. Irónicamente, unas decenas de casos de cólera lograron movilizar las voluntades políticas que miles y miles de casos de fiebre tifoidea no pudieron conmover.
Durante los años de mi interacción con Chile he tenido la oportunidad de participar en la formación de numerosos profesionales chilenos, incluyendo muchos que han alcanzado estatura nacional e internacional, como la Dra. Rosanna Lagos Zuccone y el Dr. Pablo Vial Claro, actual Decano de la Facultad de Medicina de la Universidad del Desarrollo.

En 1991, el equipo del Programa Control de la Fiebre Tifoidea se trasladó desde el edificio central del Ministerio de Salud al Hospital Roberto del Río. Conforme a las necesidades del momento, el Centro para Vacunas en Desarrollo-Chile, fue instituido para abordar una nueva problemática de salud. Los vínculos con el Servicio de Salud Metropolitano Norte y los Departamentos de Pediatría y Microbiología de la Universidad de Chile llegaron a ser aún más fuertes. La Dra. Rosanna Lagos ha sido la Coordinadora del CVD-Chile, desde el momento del nacimiento de esta nueva organización $\mathrm{y}$, a lo largo de los últimos 15 años, el trabajo realizado por CVD-Chile ha ganado un reconocimiento internacional. Producto de la visión de las autoridades locales, y de la evidencia epidemiológica y los datos de efectividad generados a través del trabajo conjunto de CVD-Chile con los equipos del Programa Ampliado de Inmunizaciones (PAI) de la Región Metropolitana, Chile fue el segundo país en desarrollo en adoptar el uso programático de la vacuna conjugada contra Haemophilus influenzae tipo b. A partir de esta decisión, las autoridades de Salud Pública Global han señalado a Chile como un ejemplo a seguir por el resto de los países en desarrollo, en lo que se refiere a la introducción racional de nuevas vacunas. La Dra. Lagos ha llegado a ser un asesor muy solicitado por la Organización Mundial de la Salud, la Organización Panamericana de la Salud, la Alianza Global para las Vacunas e Inmunizaciones Infantiles (GAVI), el Instituto Nacional de Salud de los Estados Unidos (NIH) y otras agencias internacionales. Para mí es un gran privilegio haber sido testigo del crecimiento y del prestigio alcanzado por CVD-Chile, en investigación vacunológica y en salud pública, al más alto nivel internacional. Y al hablar de CVD-Chile no puedo dejar de agradecer el generoso apoyo y los valiosos consejos de los miembros de su Directorio, el Dr. Alfredo Misraji Trajtman, 
mi amigo personal de muchos años, y el Dr. Carlos Casar Collazo.

Señoras y Señores, Chile ha cambiado enormemente desde mis primeros viajes, a fines de los años 1970. No hay más fiebre tifoidea ni cólera, y la diarrea infantil ha dejado de ser una causa de morbilidad grave y de mortalidad. La mortalidad infantil ha bajado a cifras de un dígito, casi iguales a las registradas en los Estados Unidos. Las ca- rretas tiradas por caballos que ví con frecuencia en las calles de Santiago en los años 70; los campamentos de chozas; la desnutrición severa y los brotes de sarampión han desaparecido de la Región Metropolitana y de todo el país. Chile no es más un país en desarrollo, ni siquiera un país en transición. Chile ha llegado a ser un país industrializado, con tecnología, transporte, viviendas, hospitales y universidades típicas de una na- ción desarrollada. Durante estos casi 30 años vinculado a Chile y a su gente, para mí ha sido un placer haber sido testigo de estos cambios. Más aún, el honroso reconocimiento que ustedes me entregan el día de hoy, me permite sentirme orgulloso de haber podido contribuir, con un grano de arena, a la notable trasformación socio-económica de este hermoso país y de su amable sociedad." 